\title{
Non-Programming Activities for Engagement with Foundational Concepts in Introductory Programming
}

\author{
Shuchi Grover \\ Looking Glass Ventures \\ Palo Alto, CA, USA \\ shuchi.grover@gmail.com
}

\author{
Patrik Lundh \\ SRI International \\ Menlo Park, CA, USA \\ patrik.lundh@sri.com
}

\author{
Nicholas Jackiw \\ SRI International \\ Menlo Park, CA, USA \\ nicholas.jackiw@sri.com
}

\begin{abstract}
Programming-in a text-based or visual language-is a complex activity that novices find difficult to learn. In this paper, we present an experience report on how novel activities designed for early conceptual exploration can support middle school students' engagement with and learning of foundational programming concepts beginning programmers often struggle with, specifically, variables, expressions (Boolean, arithmetic, relational), loops, and abstraction. We drew on mathematics education research on dynamic representations to design and develop a set of four nonprogramming, (open access) web-based, interactive activities and micro-worlds and two unplugged activities as part of a suite of activities that can be embedded in a typical introductory programming curriculum to introduce learners to the target concepts before they encounter them in programming. This report describes the activities as well as our experience with their use as part of an introductory computer science course in three diverse, urban, middle school classrooms in the US.
\end{abstract}

ACM Reference format:

Shuchi Grover, Patrik Lundh and Nicholas Jackiw. 2019. NonProgramming Activities for Engagement with Foundational Concepts in Introductory Programming. In SIGCSE '19: 50th ACM Technical Symposium on Computer Science Education, Feb. 27-Mar.2, 2019, Minneapolis, MN, USA. ACM, NY, NY, USA, 7 pages. https://doi.org/10.1145/3287324.3287468

\section{Introduction}

Learning to program is a central feature of most $\mathrm{K}-12$ computer science (CS) curricula. As K-12 CS education grows, stakeholders are working on varied approaches to support the development of programming skills among diverse, young learners.

Novice CS learners are typically introduced to programming in a block-based language such as Scratch, Blockly, Alice, App Inventor, and Snap!. These languages shift the programming focus from syntax to semantics since the blocks all but eliminate syntax errors. However, syntax is not the only aspect of programming that novices find challenging. Learners also struggle with learning

Permission to make digital or hard copies of all or part of this work for personal or classroom use is granted without fee provided that copies are not made or distributed for profit or commercial advantage and that copies bear this notice and the full citation on the first page. Copyrights for components of this work owned by others than the author(s) must be honored. Abstracting with credit is permitted. To copy otherwise, or republish, to post on servers or to redistribute to lists, requires prior specific permission and/or a fee. Request permissions from Permissions@acm.org. SIGCSE '19, February 27-March 2, 2019, Minneapolis, MN, USA (C)2019 Copyright is held by the owner/author(s). Publication rights licensed to ACM.

ACM 978-1-4503-5890-3/19/02...\$15.00

https://doi.org/10.1145/3287324.3287468 the semantics and pragmatics of programming, be it in a textbased [e.g 3, 15, 19] or a visual language [e.g. 5, 8, 10]. Research suggests that weak mental models and conceptual understandings prevent deeper learning of foundational CS concepts [3, 16]. Recent research on middle school programming in Scratch also found that some concepts-such as variables, expressions with variables, Boolean logic, loops (with variables), and abstractionare more difficult than others for learners [9].

To address the need to support students' early CS conceptual skill development, we designed a curriculum, 'VELA', built around programming and six non-programming activities for middle school students to learn key CS concepts: including variables, expressions, loops, abstraction and conditionals. The VELA nonprogramming activities are designed to help students explore and use these concepts in interesting ways in non-programming contexts (digital or unplugged) before they encounter them in programming contexts in environments like Scratch.

The VELA activities (along with teacher materials) and a curricular sequence involving Scratch were implemented as a 4week intervention (as part of their middle school CS course) in three diverse middle school classrooms in a large urban school district in the United States. This experience report presents our findings from this implementation as well as lessons learned. We believe this report will be valuable in informing the use of these activities and materials (available at http://csforall.sri.com) in their curriculum regardless of programming language being used.

\section{Related Work \& Research Framework}

Novices struggle with naïve notions about variable assignment (assuming variables can have multiple values at the same time) [21]; with distinguishing between what goes inside a loop and what precedes or follows a loop [3] and with designing mathematical and logical expressions and naming variables [6] Problems pertaining to the understanding of conditionals are also often attributed to a lack of understanding of Boolean operators [4]. Recent research with Scratch also reports that students struggle with constructing terminating conditions for loops involving variables and Boolean expressions [8]. Some students working in Scratch were found to believe a variable must be a letter that stands for an "unknown number" (as in math class), and students often assume multiple actions in a loop are repeated not as a block but rather individually one after the other [10].

Activities in introductory programming classrooms are often centered on open-ended projects and tinkering involving minimal guidance. Lack of conscious pedagogic attention to student engagement with conceptual ideas often exacerbates the problems 
novices face in understanding programming [16,17]. Our activity designs draw specifically on innovations in interactive dynamic representations in mathematics such as those in Geometer's Sketchpad [12] or Cabri Géometre [14]. Research has shown the important role such dynamic representations play in supporting diverse students' development of conceptual understanding in topics of algebra and geometry [2,20].

\section{Design of Non-Programming Activities for Conceptual Learning}

In this section, we describe the design and classroom use of four interactive digital activities and two unplugged activities that support early exploration and understanding of foundational CS concepts. This process entailed conceptualization, design, and development of digital (and two companion non-digital activities for introductory CS middle school curricula that can serve as precursorial "conceptual sandboxes" to explore these key concepts before employing them in programming. The names of the activities and computing concepts targeted are in Table 1.

Table 1. Non-Programming Conceptual Activities Suite

\begin{tabular}{l|l|l}
\hline Name & Type & Introductory Concept(s) \\
\hline Story Variables & Unplugged & Variables (variation, naming, types) \\
\hline Cats \& Ladders & Digital & Variables, Numeric Expressions \\
\hline $\begin{array}{l}\text { Graphical } \\
\text { Looping }\end{array}$ & Digital & Repeating pattern, Looping \\
\hline Dice Game & Unplugged & If-Then, Boolean outcomes \\
\hline Three Switches & Digital & Boolean Logic, Boolean Expressions \\
\hline Alarm Clock & Digital & $\begin{array}{l}\text { Numeric and Boolean Expressions, } \\
\text { Data Types, String Data, Modeling }\end{array}$ \\
\hline
\end{tabular}

\subsection{Activity Design Guidelines}

The activity design process was guided by a precise set of learning goals (LGs) that our activities (and companion curriculum) targeted. These LGs, informed by emergent standards and frameworks and recent research in the context of middle school programming $[1,8,13]$, are listed below.

\section{Students will learn/understand-}

1. How programs are executed sequentially

2. Simple loops (fixed/predetermined number of repetitions)

3. How to create different pathways in algorithms using conditional statements

4. Algorithmic flow of control- how instructions are executed in sequence sometimes with loops/conditionals

5. That in control structures (like loops and conditionals), a collection of an arbitrary number of statements can be declared to act as a single statement by grouping them

6. What Initialization (in general and of variables, specifically) is and why it is needed

7. That variables can only hold one value at a time

8. How types define the set of values a variable can have, and the set of operators that can be used

9. How variables are created, assigned values, and updated

10. How variable values change within loops

11. How to use expressions to make new variables from old ones

12. Boolean variables, operators \& expressions

13. How to control loops and conditionals using Boolean conditions (that may involve variables and expressions)
14. Boolean as a data type

15. How variables are an abstraction or representation of data in the program and the real world

16. Computational solutions are abstractions; and that these abstractions can be represented in different ways

17. Identifying and specifying patterns in real-world phenomena and abstracting them into structural components of program.

Guided by the LGs, the main focus of designed activities was to introduce Variables as named quantities that can change value; Expressions as defining new changing values by applying valueappropriate operations to existing variables; Looping as countable repetitions of some identifiable "repeating unit"; Abstraction as the process of giving a name to a specific collection of details to reference its purpose without quoting or enumerating its detail; and Conditionals as enabling alternate pathways that are determined based on evaluation of expressions involving arithmetic, relational, and Boolean operators.

The initial activity concepts were designed with inputs from classroom teachers from a large, diverse urban school district in Northern California in a participatory design model. Over a 12month period, the activities were iteratively designed and refined with inputs from a multi-disciplinary, multi-stakeholder team that included researchers, teachers, and students. The research team included computer scientists, CS education researchers, learning scientists, and math education researchers.

The current version of the web-based digital activities is available at (URL suppressed). We describe the activities and lesson sequence in brief in the remainder of this section.

\subsection{VELA Non-Programming Activities}

All our activities are designed to be completed in pairs along with a worksheet and intermittent whole class discussions.

3.1.1 Story Variables (Unplugged) In Story Variables, students work collaboratively in pairs to investigate a series of short "stories" all containing everyday examples of quantities that vary (Figure 1). For example, "Excuse me-last week I bought one of these pens here for $\$ 1.50$. Are you really telling me they now cost \$3?" Or "I watched the basketball game last night. At halftime we were tied, but in the end, they beat us 94-90.” Through discussions, students come up with a definition of 'variable' as a named quantity whose value can change, practice identifying and naming variables meaningfully, and analyze a variable's changing values to determine its specific types and expected ranges. Students identify their own real-world scenarios that involve "variables". As a final activity, they watch a video clip of the Pacman game and list the different variables they observe, and their ranges.

3.1.2 Cats \& Ladders (Digital) The Cats and Ladders digital "game" (Figure 2) formalizes this idea of variables as named quantities whose values can change. In the context of an interactive game that involves rescuing cats from various floors of buildings, they encounter ideas of variation (of the ladder height), data types (numerical ladder height or alphabetic building label), arithmetic expressions on varying inputs (stacking two ladders-an orange and blue one, whose heights are added to get "total ladder height", and the relevance of descriptive and meaningful names for variables in an operational context (e.g. BlueLadderHeight). The activity is divided into multiple stages, each of which is "unlocked" as the students proceed through the activity. Students also discuss the range of possible values of the variables involved. They explore abstraction through creating arithmetic expressions that 
synthesize new variables (e.g. TotalLadderHeight) from existing ones using operators.

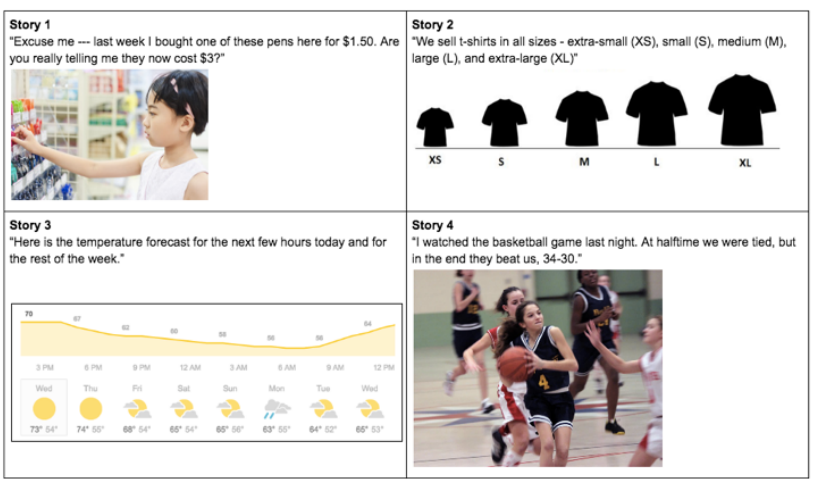

Figure 1. Real-world variables/scenarios in "Story Variables"

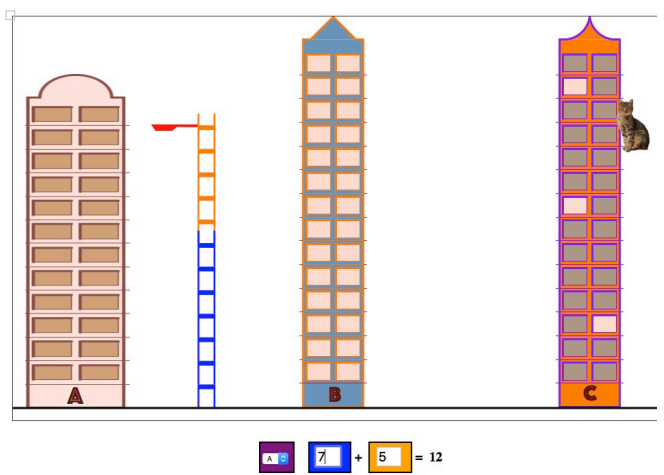

Figure 2. Screenshot of Cats \& Ladders Digital Activity

3.1.3 Graphical Looping (Digital) Here, students are introduced to sequential and iterative control flow through comic-strip panels that provide an accessible, graphical interface in which linear sequence directly shapes coherence and meaning. Students first arrange a collection of panels into "a sensible story," representing one back-and-forth lap of a swimmer in a pool (Figure 3a). They then evolve their narrative into a story with a pattern, whereby repeating the "inner story" of swimming one lap (the "repeating unit"), generates different stories in which any number of laps can be completed (Figure 3b). The dynamic visualization of the total laps with the variable number of the laps, is in essence a visual "unfurling" of a loop where the number of repeats is based on the value of a variable. Students answer questions such as: What happens when the inner story is repeated 10 times, how many pool lengths will the swimmer swim? How might the total length swum increase with each lap?

3.1.4 Dice Conditionals (Unplugged) Our introduction to conditionals involves learning how to evaluate expressions that result in a TRUE or FALSE. Through a series of fun, unplugged activities, student learn to evaluate whether or not to take a course of action. In the warmup to the game, students play "Simon Says," where all students begin by standing, and sit if a statement the teacher says is true (e.g. I am wearing sneakers) and then progress to taking action based on evaluating an IF statement (e.g. "If I am wearing sneakers, raise my right hand") and finally based on an IF-ELSE statement (e.g. "If I am wearing any red, then stand on one leg, ELSE raise your right hand"). The activity then moves to a game played in pairs with online or physical dice, where player
1 or 2 gets a point based on evaluating an expression involving arithmetic and relational operators (e.g. IF Dice1 + Dice2 $<\mathbf{1 2}$, THEN player 1 gets a point).

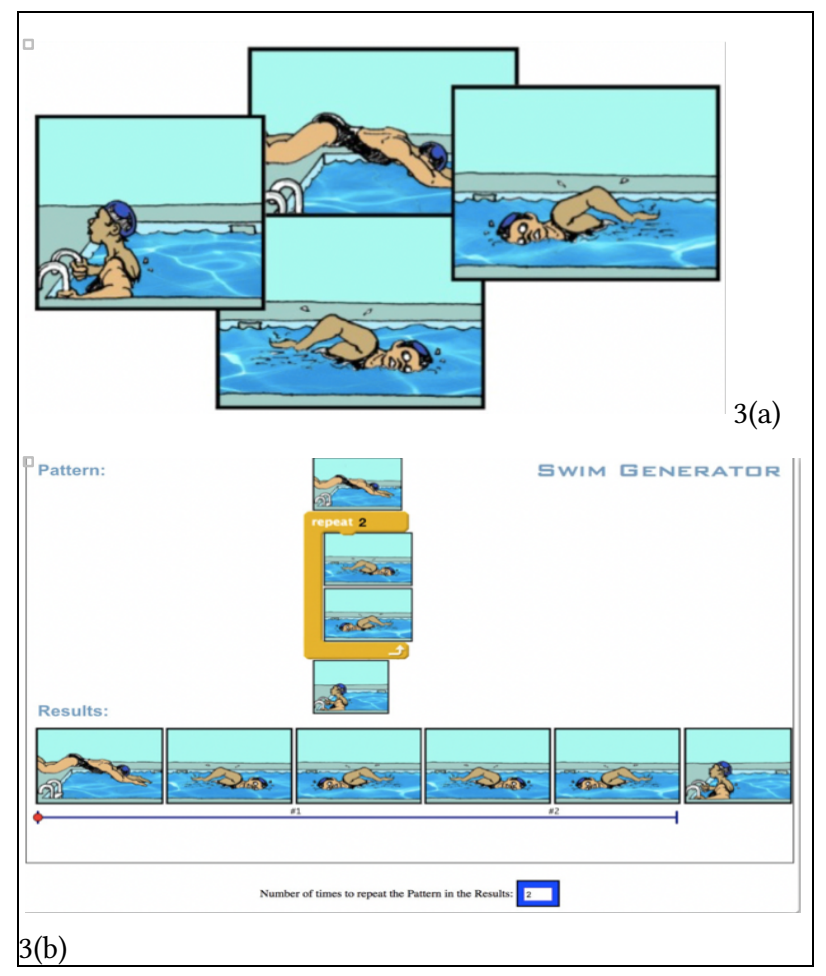

Figure 3. Screenshot of the Graphical Looping Activity

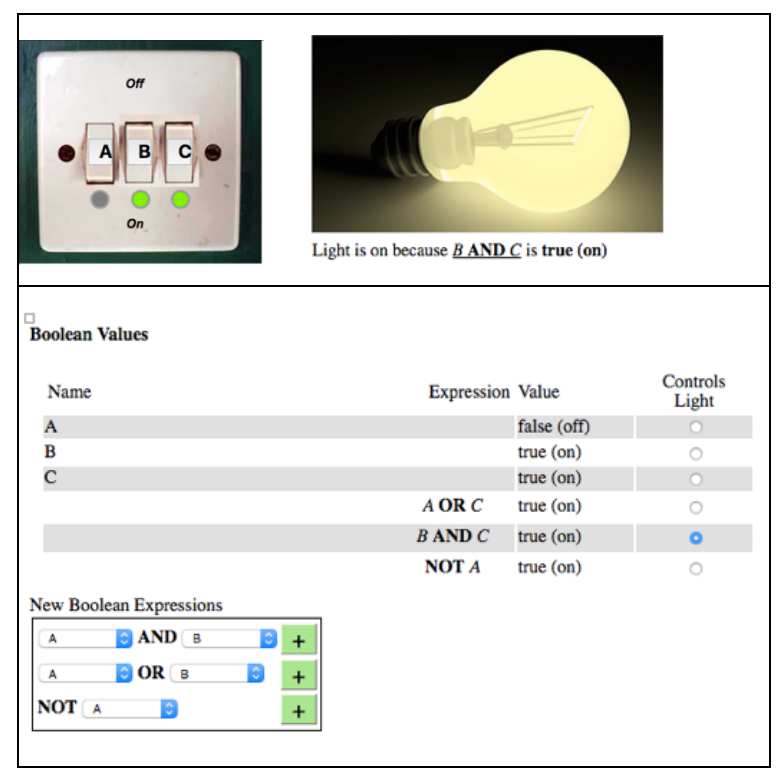

Figure 4. Screenshot of the 3 Switches Interactive Activity

3.1.5 Three Switches (Digital) Though introductory exploratory "challenges" in an interactive expression-authoring microworld, students explore how Boolean operators (AND, OR, NOT) work, and what the resulting expressions evaluate to using an example of three switches that toggle between two states - ON and OFF/ 
TRUE and FALSE (Figure 4). They then extend the ideas to create and evaluate Boolean expressions that use these operators either in simple expressions or compound expressions that combine one or more operators. The activity ends with an exploration of connections between variables and Boolean expressions in realworld scenarios through discussions, in which students articulate the outcome variable, the controlling variables, the Boolean operators used, and the Boolean expression (e.g. A car gives a warning beep if - Driver's seat-belt is not locked; Passenger's seat-belt is not locked; Car is being driven).

3.1.6 Alarm Clock (Digital) The final VELA non-programming activity uses the same underlying microworld and expression builder as Three Switches, but the context in this case is an Alarm Clock (Figure 5) that should ring at certain times e.g. to wake one up for school (or when isAlarmTime is true) based on expressions created using variables (Boolean, numerical, and string) and expressions (relational, arithmetic, and Boolean). By assigning names to these new expressions, and by incorporating those new names (rather than the full symbolic expressions defining them) into new expressions that reference those intermediate results, students develop a hierarchy of abstractions to manage the growing symbolic and conceptual complexity of a family of equations expressed only in terms of foundational variables. The activity can be expanded to be woken only on weekdays where an expression like (isAlarmTime AND isWeekday) encodes a complex amount of decision-making involving times, and day-calendars.

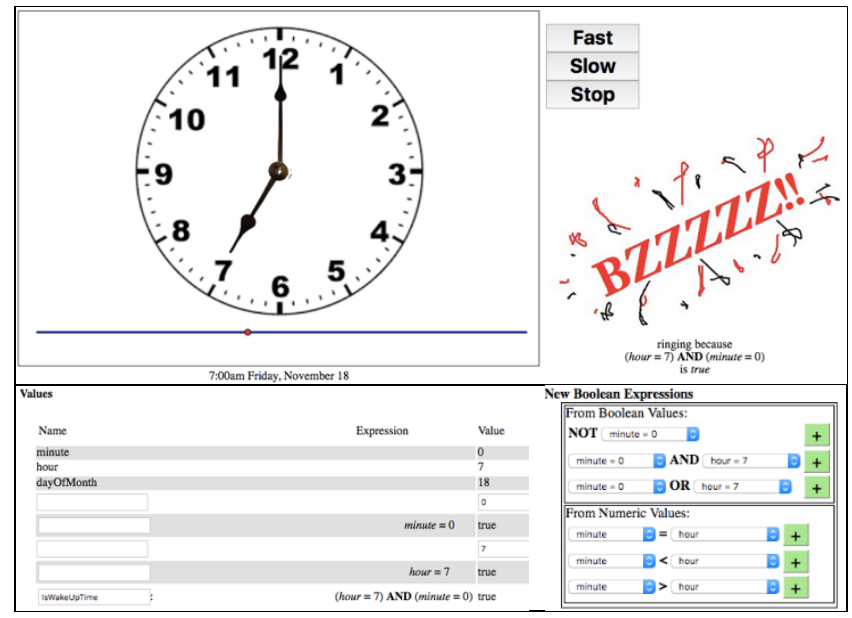

Figure 5. Screenshot of the Alarm Clock Interactive Activity

\subsection{Teacher Materials and Curricular Sequence for VELA \& Programming Activities}

Each of the non-programming activities described included teacher lesson plans, student worksheets that guided the activity trajectory (to be completed by students in pairs), and formative assessments (or "review sheets", to be completed individually). In addition to these designed activities and materials, we designed lesson plans to introduce students to basic Scratch constructs and programming concepts. The Scratch lesson plans attempted to also make connections to relevant ideas in VELA activities in an effort to mediate transfer. For example, the Scratch activities related to loops with variables made explicit connections to Graphical Looping. Learners were introduced to the idea of using a "Repeat" block to swim three laps, change the (swimmer's) Energy value, and also "watch" this value decrease (using the 'Say' block) with each lap (or iteration of the loop). They then progressed to the idea of a generalized solution where the number of laps was based on an input from the user to be used as a variable in the Repeat block (Figure 6).

All the lesson plans and materials were refined with feedback from 3 middle school classroom teachers who were planning to implement them in their classrooms. We also worked with the teachers to embed the entire VELA intervention (of nonprogramming and programming lessons) into a 20-day period within a 9-week introductory programming middle school course that they were teaching. $<\mathrm{URL}>$ shows the entire curricular sequence for those 4 weeks.

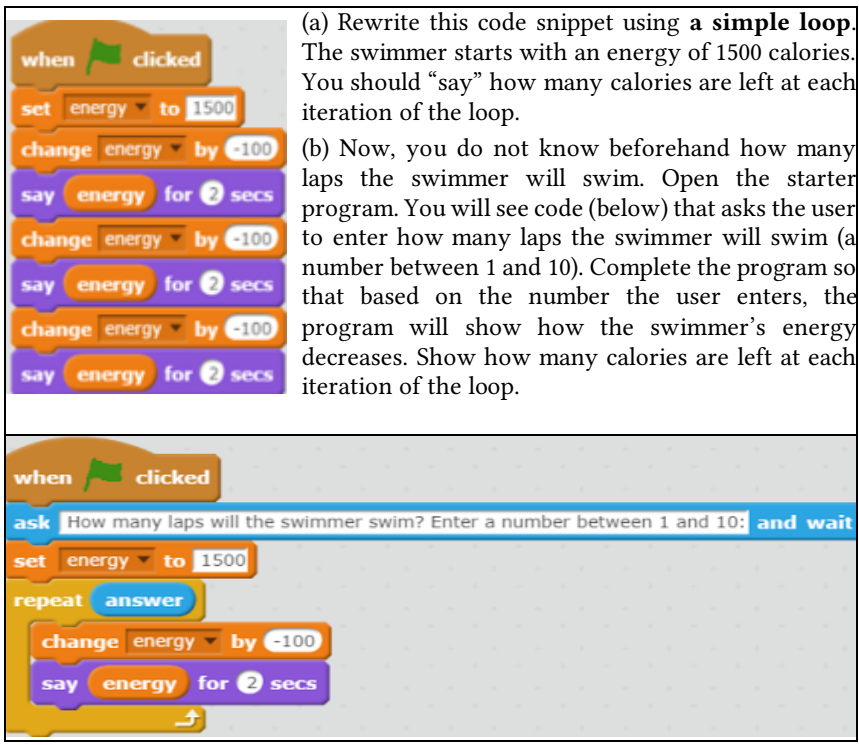

Figure 6. Scratch activities using loops and variables that bridge to Graphical Looping

\section{Classroom Study, Data Gathered \& Findings}

VELA activities and the Scratch curriculum were used in 3 middle school classrooms ( $\mathrm{N}=72$; Gr. 6: 17 male, 10 female; Gr. 7: 15 male, 16 female; Gr. 8: 11 male, 3 female) in 3 different schools in a large, diverse, urban school district in the U.S., as part of an introductory CS course. Grades 6 and 8 schools serve high-poverty and underserved populations, whereas grade 7 was in a highachieving school. The three teachers participated in 20 hours of professional development before implementing the curriculum. We gathered data on (a) Pre-post assessment scores from an assessment [7] that we designed through iterative rounds of piloting in classrooms and the use of a robust assessment design framework. It included multiple-choice and open response question types using snippets of Scratch code, or real-world (narrative) scenarios; (b) Post-survey on students' reactions to the activities; (c) Classroom observations when the nonprogramming activities were used; (d) Teacher and Student interviews; (e) Final (open-ended) projects in Scratch done (individually or in pairs) that we analyzed using an elaborate rubric [11]. The rubric supports analysis for correctness as well as program sophistication. We compared these to final Scratch projects from $\sim 60$ students randomly selected from middle school classrooms across the district who were not part of this study (who used a version of [22] as their introductory CS course); and 
(f) Prior academic preparation (math \& English scores) and ethnicity provided by the district (anonymized).

\subsection{Findings}

This section presents salient findings from statistical analyses of posttest scores and learning gain (pre-to-post change).

- All three classrooms showed statistically significant gains on the pre-post assessment (Table 2).

- $\quad$ Grades $7 \& 8$ had statistically higher pre- and post-scores than Grade 6, and there was no statistical difference between Grades $7 \& 8$ pre- or post-score.

- No differences by gender in pre-/post-score or learning gain

- $\quad$ Prior math score significantly predicted pre-score; English did not. However, when controlling for pre-score, neither math nor English were significant predictors of post-score.

- Ethnicity-wise distribution of students was uneven and sample sizes very small for some groups. That said, there were no significant differences by ethnicity in post-score or learning gain.

- Learning gain was not statistically different by gender, grade, ethnicity, or prior math or English score - i.e., the intervention showed no significant difference in learning gains in students by gender or prior academic preparation, and all grades showed statistically similar learning gains.

Table 2. Student pre-post results on VELA assessment

\begin{tabular}{|c|c|c|c|c|}
\hline & pre & post & $\mathrm{p}$ & Cohen's $d$ \\
\hline Grade6 $(\mathrm{n}=26)$ & 39.2 & 52.5 & 0.00 & 0.65 \\
\hline Grade7 $(\mathrm{n}=31)$ & 65.5 & 80.0 & 0.00 & 1.02 \\
\hline Grade8 $(\mathrm{n}=14)$ & 56.3 & 68.5 & 0.00 & 0.67 \\
\hline
\end{tabular}

Table 3. Average scores on final open-ended projects for VELA ( $\mathbf{N = 5 4 )}$ and non-VELA students $(\mathrm{N}=60)$

\begin{tabular}{l|ccc}
\hline & VELA & Non-VELA & $\mathrm{p}$ \\
\hline Total Score & 96.0 & 71.8 & 0.01 \\
\hline General Factors & 31.4 & 29.2 & 0.22 \\
Mechanics of Design & 17.5 & 16.4 & 0.67 \\
User Experience & 4.6 & 3.4 & 0.93 \\
Basic Coding Constructs & 31.83 & 18.17 & 0.00 \\
Advanced Constructs & 10.72 & 4.6 & 0.01 \\
\hline Variables & 1.3 & 0.9 & 0.10 \\
Boolean Operators & 2.8 & 0.9 & 0.01 \\
Relational Operators & 4.3 & 2.7 & 0.06 \\
Repeat-Until Loops & 1.7 & 1.1 & 0.21 \\
\hline
\end{tabular}

A comparison of scored free-choice final projects of our sample students and those of a comparison sample from the same district showed significantly better performance by VELA students (for all three grade levels) especially on coding constructs and the use of operators. Use of 'Variables', and 'Repeat-untils' also showed higher (though not statistically significant) use on average in VELA projects than non-VELA projects (Table 3).
Table 4. Student and teacher reactions to the activities

Teacher and Student Reactions to Cats \& Ladders

Teacher: "maybe it is having that tool that reaches the student on so many levels being that it is animated, there is sort of an emotional interest, all of that, so that story sticks out better. And so it may not really have huge payoff in that it shows you how to build an expression, but as the teacher emphasizes over and over again now that expressions are made from variables and operators and how that comes up later, it refers back to cats and ladders it is like oh yeah, cats and ladders, the two ladders, the two ladders. So the power becomes more on how the teacher refers back to the tool in later discussion in referencing the story plots." $7^{\text {th }}$ Grade Student: "I thought it was interesting because this happens in real life, and I like cats, and I like the idea of saving them..I thought it was more challenging and interesting because you would have to not only type in the blue ladder height and orange ladder height, but also which building it was in. It made it more connected to realize because in the city that I live in, there's a lot of buildings."

$8^{\text {th }}$ grade student:"It's... to show us about height. And like the variables change. Because like you could change the numbers...It shows us variables. Like how high the ladder could go, like how we could change it."

$6^{\text {th }}$ Grade Student: "Cats \& Ladders was fun and cool" (a few other students had similar reactions)

$7^{\text {th }}$ Grade Student: "I liked cats and ladders because it was like a real game."

Student Reactions to Graphical Looping

$8^{\text {th }}$ Grade Student: "It's sort of like a puzzle...It teaches you the purpose of what loops do...It reminded like if we go to a grocery store and we could come back and get more food from there and then come back...Like each day like ... it can be from like school, you go back home. And from the home you go back to school" $7^{\text {th }}$ Grade Student: "Graphical Looping was too easy and boring" (a few other students had similar reactions)

\begin{tabular}{l}
\hline \multicolumn{1}{|c|}{ Teacher and Student Reactions to Alarm Clock } \\
\hline$\frac{6^{\text {th }} \text { Grade Student: "I did not really understand it" }}{8^{\text {th }} \text { Grade Student: "I liked alarm clock the most because it was }}$ \\
most challenging" \\
$\frac{8^{\text {th }} \text { Grade Student:" It was most interesting" }}{6^{\text {th }} \text { Grade Student: "It took too long" }}$ \\
Teacher: ""And then the Boolean 3 switches and the alarm clock, \\
I think are too big for the kids, as an activity to handle on their \\
own. And so they become very teacher directed, and along that \\
way you lose a lot of kids.." \\
Teacher: "The interface is confusing, in particular with regard to \\
drawing attention to which features are more important than \\
others... Some kids might get it and understand what to ignore \\
and what to work with, but it's not clear at first. And so even \\
some of the naming schemes for what the boxes are, what the \\
tables are, this table is how you're going to use this, and this table \\
is how you're going to use that.
\end{tabular}

Students' post-survey feedback and teacher interviews (Table 4) reflects that, overall, students found Cats \& Ladders to be most engaging and fun, Graphical Looping activity was found to 
be lacking in challenge by some, though students readily made real-world connections, and the micro-world expression-building interface for Three Switches and Alarm Clock was confusing for some students. Additionally, one teacher noted that on the topic of abstraction, the bridging between the Scratch activities and the VELA activities should be stronger. One teacher said that while students were highly engaged with the activities and they learned, they would benefit from more time to return to the ideas, solidify them, calibrate misunderstandings, and build deeper understanding over time.

Our classroom observations revealed that teachers' challenges keeping students on topic, the number of students in class, and classroom cultures that did not always support studentdriven whole class discussion. The paired activities also lacked explicit strategies for supporting collaboration.

At the same time, one of the teachers felt strongly that participating in the PD and teaching the activities deepened her own conceptual understanding, especially of abstraction. She recommended that the activities (especially those relating to Boolean expressions and abstraction) be used in the district teacher PD- "I felt like it really educated me quite a bit, deeply and powerfully. And so it was a huge learning process for me, not quite on the level of how to be a teacher in the classroom, but the content itself. So it developed my content knowledge really well. And I'm excited to now kind of apply it in the classroom, and try to marry our current curriculum to some of these ideas and flesh it out more."

\section{Lessons Learned}

Reflecting on our findings, some particular insights may inform future use of these activities.

1. All three classrooms showed significant gains on the pre-post assessment (see Figure 1). Examining the VELA classroom as a curricular activity system, we see that students engaged well with many of the VELA activities, demonstrating promise of our approach, our digital and unplugged activities, and relevant examples and contexts.

2. One of the most promising findings that points to the value of using this curriculum widely is that learning gains were not linked to specific grades or student characteristics (gender, prior math/English scores). It demonstrates the promise of this approach and curriculum to reach all students regardless of prior academic preparation.

3. The finding that students' use of more Boolean operators and Repeat-untils in their free-choice final projects suggests that our strategy to deliberately introduce these key concepts impacted transfer to programming. This is significant since these topics are often ignored in programming curricula despite being listed in CS frameworks and standards [1,13]

4. Our activities need to be refined to incorporate better ways to engage younger learners (in grade 6), as their performance in the pre-posttest left much room for improvement. We also need to determine if the assessment itself is better suited to grades 7 and 8 students by studying it more widely with larger samples. Also, the wording of one question in the test was found to be ambiguous and is being improved upon. The assessment and related analyses can be found in [7].

5. Classroom culture needs attention when using a curriculum like this. Even in the high achieving school (grade 7), there were issues with regard to time for exploration, pacing, differentiation, leveraging whole class discussions productively, trouble shooting opportunities, and iterations of key learning moments. Evidence related to the relationships between instruction, classroom environment, and the activities raised questions about how to deepen students' engagement with, and learning of, our target programming concepts. We found that students needed time to explore the concepts in different ways through the activities, opportunities to collaborate with peers in order to problem solve together, have their own thinking articulated and challenged, and to return to prior learning experiences to iterate on their growing conceptual insights. Unfortunately, when teachers make instructional choices to address these needs, they have to concurrently contend with the limits of the system, such as class size, varied levels of student understanding, time, student habits and mindsets, as well as their own beliefs and practices.

6. One teacher felt that given the number of students and time constraints, she could only do superficial differentiation. This was reinforced by our classroom observations.

7. Our unique conceptual activities can also be used for CS teacher PD (as one of the teachers noted) to introduce novice CS teachers to-and deepen their understanding offoundational concepts, and especially Boolean expressions and abstraction.

8. Perhaps our most gratifying takeaway from this project is that at the urging of our participant teachers, the district has incorporated most of our non-programming activities into their regular introductory middle school CS course, as a result of which our unique conceptual activities are reaching over 10,000 students in the large urban school district.

\section{Conclusion}

In this experience report we described our unique innovation-a suite of non-programming activities for introducing learners to variables, expressions, loops, conditionals, Boolean logic, and abstraction-that targets these concepts that novice learners often find challenging. We shared results from the use of these digital and unplugged interactive activities in grade 6,7, and 8 classrooms in a large urban district in the U.S., representing ethnic and socioeconomic diversity. Our findings reflect the promise of our approach while our lessons learned provide useful pointers for others who may be interested in using these activities as part of their introductory CS course (using any programming language).

\section{ACKNOWLEDGMENTS}

We thank NSF (\#1543062) for grant funding. Thanks to Matthias Hauswirth, Jeremy Roschelle, Satabdi Basu and SRI colleagues, Bryan Twarek, Xander Piper, and middle school teachers and their students for participating and partnering in this research. 


\section{REFERENCES}

[1] Computer Science Teachers Association. 2017. CSTA K-12 Computer Science Standards, Revised 2017. Retrieved from http://www.csteachers.org/standards.

[2] Drijvers, P., Kieran, C., Mariotti, M. A., et al. (2010). Integrating technology into mathematics education: Theoretical perspectives. In C. Hoyles , \& J. P. Lagrange (Ed.), Mathematics education and technology-rethinking the terrain (pp. 89-132). New York, NY: Springer.

[3] du Boulay, B. (1986). Some difficulties of learning to program. Journal of Ed Computing Research, 2(1), 57-73.

[4] Ebrahimi, A. (1994). Novice programmer errors: Language constructs and plan composition. International Journal of Human-Computer Studies, 41(4), 457-480.

[5] Franklin, D., Skifstad, G., Rolock, R., Mehrotra, I., Ding, V., Hansen, A., ... \& Harlow, D. (2017, March). Using upper-elementary student performance to understand conceptual sequencing in a blocks-based curriculum. In Proceedings of the 2017 ACM SIGCSE Technical Symposium on Computer Science Education (pp. 231-236). ACM.

[6] Gobil, A. R. M., Shukor, Z., \& Mohtar, I. A. (2009). Novice difficulties in selection structure. In International Conference on Electrical Engineering and Informatics, 2, 351-356. New Jersey, USA: IEEE.

[7] Grover, S. 2019. An Assessment for Introductory Programming Concepts in Middle School Computer Science. In Proceedings of the 2019 Annual Meeting of the National Council on Measurement in Education (NCME), Toronto, CA

[8] Grover, S., Pea, R., Cooper, S. (2015). Designing for Deeper Learning in a Blended Computer Science Course for Middle School Students. Computer Science Education, 25(2), 199-237.

[9] Grover, S., Pea, R. \& Cooper, S. (2016). Factors Influencing Computer Science Learning in Middle School. In Proceedings of the 47th ACM Technical Symposium on CS Ed. (SIGCSE '16). ACM.

[10] Grover, S. \& Basu, S. (2017). Measuring Student Learning in Introductory BlockBased Programming: Examining Misconceptions of Loops, Variables, and Boolean Logic. In Proceedings of the 48th ACM Technical Symposium on Computer Science Education (SIGCSE '17). Seattle, WA: ACM.
[11] Grover, S., Basu, S., \& Schank, P. 2018. What We Can Learn About Student Learning From Open-Ended Programming Projects in Middle School Computer Science. In Proceedings of the 49th ACM Technical Symposium on Computer Science Education (pp. 999-1004). ACM

[12] Jackiw, N. 1991, 2009. The Geometer's Sketchpad (computer software V1, V5). Emeryville, CA: Key Curriculum Press.

[13] K-12 CS Framework Committee. 2016. K-12 Computer Science Framework. Retrieved from http://www.k12cs.org.

[14] Laborde, J. M, \& Strässer, R. 1990. Cabri-géomètre: A microworld of geometry for guided discovery learning. Zentralblatt für didaktik der athematic, 90(5), 171-177.

[15] Lahtinen, E., Ala-Mutka, K., \& Järvinen, H. M. (2005). A study of the difficulties of novice programmers. ACM SIGCSE Bulletin, 37(3), 14-18.

[16] Mayer, R. E. (2004). Should there be a three-strikes rule against pure discovery learning?. American Psychologist, 59(1), 14.

[17] Pea, R., \& Kurland, D. (1984). On the cognitive effects of learning computer programming. New Ideas In Psychology, 2, 137-168

[18] Pears et al. (2007). A Survey of Literature on the Teaching of Introductory Programming. In Proceedings of the 38th Technical Symposium on CS Education. ACM.

[19] Robins, A., Rountree, J. and Rountree, N., 2003. Learning and teaching programming A review and discussion. Computer scien education, 13(2), pp.137-172.

[20] Roschelle, J. et al. (2010). Integration of technology, curriculum, and professiona development for advancing middle school mathematics: Three large-scale studies. American Educational Research Journal, 47(4), 833-878.

[21] Samurcay, R. (1989). The concept of variable in programming: Its meaning and use in problem-solving by novice programmers. In E. Soloway and J. C. Spohrer, editors, Studying the Novice Programmer, 161-178.

[22] Schofield, E., Erlinger, M., \& Dodds, Z. (2014). MyCS: CS for middle-years students and their teachers. In Proceedings of the 45th ACM technical symposium on Computer science education (pp. 337-342). ACM. 